more, when the intensity of the radiation in question is increased enormously (as by using daylight), the reaction velocity does not show a corresponding increase.

Experiments with nitrogen peroxide, hydrogen, and iodine vapor have proved that the heat conductivity of dissociating gases is many times greater than that of similar gases which do not dissociate. The increase in heat loss from small wires, due to the dissociation of a surrounding gas, is often more than ro times the total energy radiated from the wire. On the basis of the radiation hypothesis, however, the dissociation entails an absorption of radiation and thus could produce only a decrease in the heat lost from the filament. These experiments furnish conclusive evidence against the radiation hypothesis.

The similarity between the Arrhenitus and the Wien equation thus results from the fact that both reaction velocity and radiation are fundamentally dependent upon phenomena involving probability. Both equations can be derived from the same statistical law. It is shown that the energy for the activation of molecules must be derived from internal energy of the molecules. This concinsion involves certain very fundamental dificulties, but it is shown that these are of the same nature as those that are encountered in the theory of the photoelectric effect, thermicnic emission, and other phenomena involving quantum relations.

SOXENECTADY, N. Y.

WORTY-SECOND CONTRIBUTION FROM THF COLOR IABORATORY, U. S. BURAAU OF CHEMISTRY.]

\title{
THE INDEPENDENT ORIGIN OF ACTINIUM.
}

\section{By EILIOT QUNNCY ADAMS.}

Received August 27, 1920.

Actinium has been shown ${ }^{1}$ to be derived from Antonoff's "uranium $Y$, , isotopic with uranium $\mathrm{X}_{1}$ (and thorium)-through a long-lived intermediate variously known as uranium $Z$, eka-tantalum and protactinium. This element, as the second name indicates, is homologous to tantalum and is isotopic only with brevium (uranium $\mathrm{X}_{2}$ ). The production of uranium $\mathrm{Y}$ from chemically pure uranium shows that it must be derived by an $\alpha$-ray transformation frotn uranium or an isotope of uranium. Hahn and Meitner ${ }^{2}$ believe that Hönigschmid's value (206.05) for the atornic weight of uranium-lead proves uranium $Y$ to be derived from uranium $\mathrm{II}$, since $3 \%$ of actinum-lead of atomic weight 2 Io (if uranium $\mathrm{Y}$ were derived irom uranitum I) would raise the mean to 206.I2. The suggestion

1 Frederick Soddy and John A. Cranston, Proc. Roy. Soc. 94A, 384-404 (1918); Otto Hahn and Lise Meitner, Ber., 52B, r812-28 (x919); Physik. Z., 20, 529-33 (1919).

: Loc. cit 
of Piccard ${ }^{1}$ that uranium $\mathrm{X}$ is derived from actino-uranium, an isotope of uranium, has been held by Soddy and Cranston ${ }^{2}$ to involve the assumption that the periods of uranium I and actino-uranium must be the same.

This assumption is by no means necessary, as the following considerations will show. For the actinium-uranium ratio to remain constant with respect to time would, indeed, require equality of period of uranium I and actino-uranium. The experimental results, however, do not show constancy with respect to time; they demonstrate approximate constancy with respect to place. If the isotopes were thoroughly mixed before the beginning of the geologic history of the earth, and if neither of them has since been supplied from another source (as the disintegration of an unknown radio-element of comparable period), their ratio should be the same everywhere on the earth at any time, but should everywhere change progressively at a rate dependent on the difference in period of the 2 isotopes. The enormous periods make the detection of such a "secular shange" in the ratio a matter of extrene difficulty.

By analogy with tranium-lead (206.00) and thorium-lead (208.00), actinum-lead should have an atomic weight of 207 , giving for (uranium $+3 \%$ actinium)-lead a mean value of 206.03 , which agrees well with Hönigschmid's 206.05 , particularly as the presence of thorium-lead or any ordinary lead would make the experimental figures too high.

The relation between the 3 series is shown in the table. For the sake of symmetry the actinium series begins with a hypothetical $\beta$-ray element of valence 5. Since the longest-lived of the known $\beta$-ray elements, radium $D$, has a half-period of only 24 years, the assumed element must, ages ago, have disintegrated quantitatively to form actino-uranium. The table gives the atomic weight and valence of each element and the type of radiation given out in each transformation. The 2 sub-groups of the Mendeleeff table are indicated by the letters $A$ and $B$. The names "radium. emanation," "actinium emanation" and "thorium emanation" have been shortened, respectively, to "radon," "actinon" and "thoron," names which suggest that the element in question is an inert gas. ${ }^{3}$ The valences given in black-faced type point out the return to the original valence after 3 transformations and, with change from the A to B sub-group, after 7 more transformations. The valences given in italics show a similar repetition of the valence IV, 3 and 10 steps before the final product (lead).

Since each line represents a step in the disintegration, where both $\alpha$ -

${ }^{3}$ A. Piccard, Arch. Sci. Phys. Nat. [4], 44, I6r (r917).

2 Loc. cit.

"The name "niton" suggested by Ramsay fails to show the relation of the el ement to radium. It might be well, similarly, to change "helium" to "helion." The former name was given by Lockyer to what he believed to be a metallic element in the sur. 
and $\beta$-changes occur with the same element the products will be given together on the line below, the one occurring in smaller amount being in parenthesis. It will be noted that radium $D$ is given as the common product of raditum $\mathrm{C}^{\prime}$ and radium $\mathrm{C}_{2}$, thorium-lead as the common product of thorium $\mathrm{C}^{\prime}$ and thorium $\mathrm{D}$, etc. While such identity has not been proved,-and indeed could be proved only in the first instance, until means are perfected for detecting and separating non-radioactive isotopes, - it seems unreasonable to assume unnecessarily the possibility of isotopes of the same atomic weight. No instance of such elementary isomerism has yet been established. ${ }^{1}$

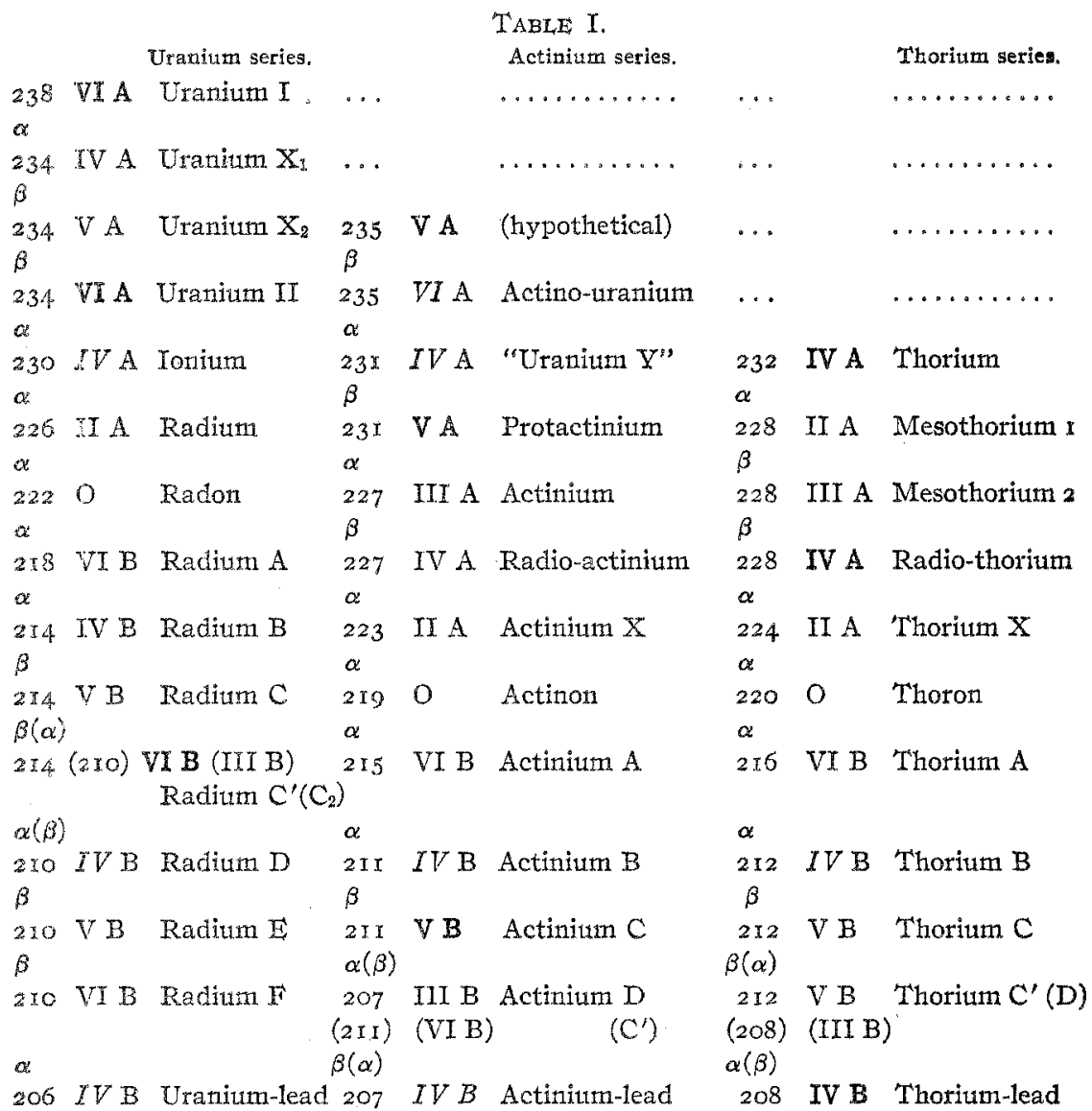

The atomic weight and valence relations are simply explained by the assumption that ( $I$ ) the hypothetical first member of the actinitum series and (2) thorium differ from uranium by the replacement of, respectively,

1 If actinium were a branch product of uranium I or II, there would be several stich cases. 
one and two $\alpha$-particles by hydrogen ions. The latter are not lost in the radioactive disintegration and increase comespondingly the atomic weight of the lead finally resulting. It is interesting to note that in the actinium series (with presumably an odd number of hydrogens in the atomic nucleus) the tendency shown in the uranium and thorium series for $\beta$-particles to come off in successive transformations is replaced by a tendency to come off in alternate transformations.

As Soddy and Cranston have pointed out the actinium series differs from the uranium series so markediy,--particularly in the constant of the Geiger-Nuttall relationship between period of transformation and range of $\alpha$-particles emitted,-as to favor the "suggestion that the actinium and radiun families tnay be quite distinct."

\section{Summary.}

1. The asstumption (made by Piccard) that the actinium series is de. rived neither from uranium I nor from uranium II, but from a third isotope (actino-uranium) does not require (as Soddy supposed) the identity of period of the first and third.

2. The relation of the 3 series (uranium, actinium and thorium) becomes more symmetrical if a hypothetical isotope of protactinium ( = eka. tantalum $=$ uranium $Z$ ) be assumed as the parent of actino-uranium by a $\beta$-ray transformation.

3. This element, and likewise actino-uranium are predicted to have an atomic weight 235 , corresponding to protactinium $23 \mathrm{I}$, actinium 227 and actinium-lead 207 .

4. This last value agrees well with Hönigschmid's value of 206.05 for the atomic weight of urasium-lead containing approximately $3 \%$ of actinium lead.

WABHINGTON, D. C.

[CONTRtbUTION FROM THE CHEMICAL LABORATORY OH THE UNIVERSITY OF Michigan.]

\section{PERCHLORIC ACID AS A DEHYDRATING AGENT IN THE DE- TERMINATION OF SILICA.}

BY H. H. WILYARD AND W. E. CAKE. Received August 30, 1920.

In the determination of silica the latter is usually rendered insoluble by evaporating the hydrochloric acid solution to dryness and dehydrating the residue at $100^{\circ}$ to $120^{\circ}$. This method requires considerable time, and a small amount of silica passes into solution when the salts are dissolved out by acid. Efforts have been made to dehydrate the silica in other ways which would be more rapid and equally or more effective. Drown ${ }^{2}$ first suggested the use of hot conc. sulfuric acid as a dehydrating

'Loc. cit.

3 Drown, J. Inst. Min. Eng, 7, 346 (1879). 